\title{
HOW COVID-19 ENABLED A GLOBAL STUDENT DESIGN TEAM TO ACHIEVE BREAKTHROUGH INNOVATION
}

\author{
Elfsberg, Jenny Victoria (1); \\ Johansson, Christian (1); \\ Frank, Martin (1); \\ Larsson, Andreas (1); \\ Larsson, Tobias (1); \\ Leifer, Larry (2) \\ 1: Blekinge Institute of Technology; \\ 2: Stanford University
}

\begin{abstract}
This is a qualitative single case study of a geographically distributed student team that experienced a quite different graduate course, compared to previous year's. This was due to the restrictions placed upon them following coronavirus lockdowns. With already ongoing research, and continuous development of the course, the authors had documented individual reflections and identified patterns and behaviours that seemingly determined the quality of the end result, as well as the students expectations and experiences. Semi-structured interviews, surveys and the author's individual reflection notes were already in place as part of the larger research scope and when the student team during the covid-19 year showed unexpected performance and results, the authors decided to pause the larger research scope and focus on this unique single case and capture those learnings. Not knowing how the Covid-19 situation evolves and leaning on insights from previous years, as well as this unique year, the aim with this paper is to describe the unique Covid-19 year amd share knowledge that can help improve and evolve the development of this longlived collaborative graduate student course, and other similar distributed team contexts.
\end{abstract}

Keywords: Design education, Case study, Teamwork, User centred design, Design learning

\section{Contact:}

Elfsberg, Jenny Victoria

Blekinge Institute of Technology

Vinnova

Sweden

jxe@bth.se

Cite this article: Elfsberg, J. V., Johansson, C., Frank, M., Larsson, A., Larsson, T., Leifer, L. (2021) 'How Covid-19 Enabled a Global Student Design Team to Achieve Breakthrough Innovation', in Proceedings of the International Conference on Engineering Design (ICED21), Gothenburg, Sweden, 16-20 August 2021. DOI:10.1017/pds.2021.432 


\section{INTRODUCTION}

To prepare graduates for working life, some engineering programs field curricula that implement problem-based learning (PBL) with design thinking principles, in collaboration with international companies and institutions, to realistically train students in real-world problem-solving practices (Jackson \& Buining, 2011). One example is the ME310 graduate course at Stanford University (Carleton \& Leifer, 2014). Students are trained in human-centred, design thinking principles to address wicked problems in distributed teamwork mode, progressing iteratively in divergent-convergent cycles of ideation, prototyping, and testing (Dym, et al., 2005). Industrial partners present challenging project prompts that require students to use creative, analytical, and collaborative abilities to develop and produce their solutions to highly complex and ambiguous problems.

This paper, written from a teaching and a corporate perspective, focuses on the cohort consisting of Stanford University, Blekinge Institute of Technology (BTH), and Volvo Construction Equipment, a subsidiary of Volvo Group that develops, manufactures, and markets equipment for construction and related industries globally. The two teaching teams form local teams of students with 3-5 students each to jointly address a corporate prompt, teach them design thinking principles, and coach them through the process. The goal is to provide a learning environment that entices students to independently navigate the innovation landscape in the skilful hunt for the next "big idea" (Steinert \& Leifer, 2012) thus crossing the metaphorical threshold towards becoming design thinking engineers. Exhibiting exceptionally good aptitude means that the team achieves what is called "triple wow", meaning breakthrough performance along three complementary dimensions: design, engineering, and business model.

The authors, representing the teaching teams and the corporate, formed a supporting cohort, that observes, supports, and coaches the teams through their triple loop learning process (Leifer \& Steinert, 2011). Promising and concerning team behaviours are observed and shared among the cohort, sometimes leading to encouragement, gentle nudging, or more explicit interventions. A mild form of intervention that has proven to be effective is to remind the team to ask themselves WHY and letting those answers guide them in the right direction. ME310 is a substantial commitment both financially and effort-wise, and because of this, rich documentation is generated by all involved, to prove value to executive management and to provide qualitative data for research. The ambition has been to reflect and take stock of what has gone well, what could have been done better, and what might improve future iterations.

This became particularly interesting during the academic year 2019/2020, where the fall and most of the winter quarter offered the usual observations, but when the coronavirus pandemic dawned, few things were normal and based on previous year's data this year's students would not be able to deliver a triple wow. The team exhibited team dynamics and distributed collaboration characteristics that have been proclaimed as mere potentials (Larsson, et al., 2003) and as they achieved an unexpected "triple wow", the authors decided to pause other related research and explore what lessons can be drawn for following years, and future research.

Hence, the objective of this paper is to investigate an unusual ME310 year from a backdrop of previous "normal" years to understand what new insights could enable triple-wow performance from student teams.

\section{BACKGROUND}

ME310, a graduate school course at Stanford University's Mechanical Engineering Program, was first launched in 1967 and might be the world's longest-running engineering design capstone course (Carleton, 2019) featuring masters' students in mechanical engineering and adjacent fields from Stanford and international partner universities, one of them being BTH in Sweden. It also serves as a study case and testbed for academic research, mainly for the Center for Design Research at Stanford University (Carleton, 2019), offering insights about team dynamics, global networked innovation etcetera (Carleton \& Leifer, 2014). Stanford is the "epicenter" of the global network of schools, companies, and coaches that are affiliated with ME310, and the course combines interdisciplinary teaching and problem-based learning for engineering design. Every school brings a unique strength and corporate sponsors provide funding and project prompts. A diversity of perspectives and skills, an iterative design process (Lande \& Leifer, 2009), a balance between deep reasoning questions and 
generative design questions (Eris, 2003), and positive team dynamics (Jung \& Leifer, 2011) maximizes the chances of breakthrough innovation.

The learning objectives of the course are to have students 1) produce a pre-production proof of concept prototype of a refined solution from a given prompt, 2) be able to develop and evaluate engineering requirements, 3) foster team building and teamwork skills, and 4) develop individual skills such as project management and planning (Lande \& Leifer, 2010).

The course syllabus is oriented on three workstreams (Figure 1) that coincides with the three quarters of the academic year. As the course begins in September, the Stanford students spend the first few weeks attending lectures in design thinking, training in potential solution technologies (e.g., microcontrollers, system on a chip, single-board computers), building a course culture and put emphasize on user-centric design through designing, building, and racing cardboard bikes, "the paper bike design exercise". In time for the corporate project start, the project teams are formed. The BTH students work on ME310 as part of their final-year master thesis. Only having to field one team of 3-5 students, they are selected based on performance in a one-day hackathon-style design event, where they work on a wicked-problem challenge, with supervision and coaching from the teaching team. Coaches observe to gauge who copes with ambiguity, addressing the challenge with a mix of creative and engineering mindset to tell a compelling story of their prototypes. The ones that perform best are offered to join. The students work iteratively in divergent and convergent modes to turn concrete empathic observations of user "pains" into prototypes that are challenged and proven through testing.

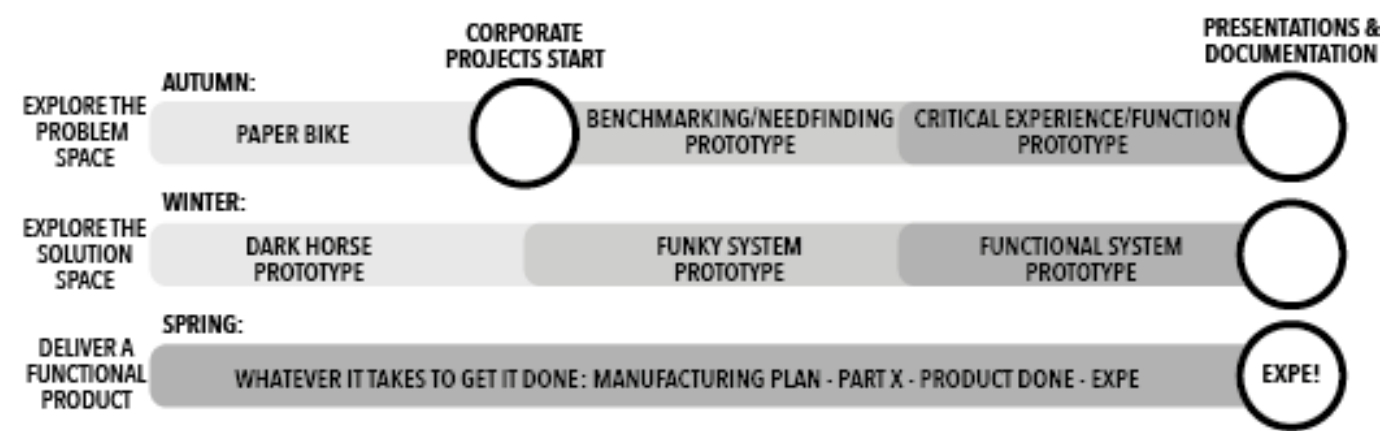

Figure 1. ME310 syllabus yearly overview (adapted from Schar, 2012)

The corporate project prompts are presented to the global teams in October. The first quarter is mainly focused on exploring the problem space, where the global team perform its first iterations of needfinding and benchmarking as well as get to know each other through team building activities. Here, uncovering the user's "jobs-to-be-done" (Ulwick, 2017) and building "the right it" (Savoia, 2019) is predominantly in focus. There is a bias towards action where the students demonstrate learnings via a range of prototypes. Examples include the Critical Experience and Critical Function Prototypes, which are only just as high fidelity to enable a tester to offer feedback and the team to infer insights from testing them, thus simplifying any decision to discard them in search of answering further questions.

At the end of the first quarter, the team documents and presents their findings in a report, enabling feedback and grading from the teaching team, and a decision on which problem sets to converge on.

The middle part coincides with winter quarter, where the team should take their understanding of the problem further into design space exploration, with a view of reaching a convergence towards a concept that should be their final solution. Here the first iteration deals with the so-called Dark Horse prototype (Bushnell, et al., 2013). The team aims for an audacious goal and where success is measured not by a positive outcome, but by the learning derived from testing. Then the students move towards a system view of their prospective solution, first with the Funky prototype, where they hack things together with bits and pieces and duct tape to keep learning about what to develop without worrying too much about the details. The second iteration of the Functional prototype is more polished and closer in resemblance to a final system. When or if they run into a dead-end, they can pivot towards some other solution space. Therefore, the team must maintain focus on need-finding and benchmarking throughout the project. The winter quarter also ends with a report, enabling feedback, grading and team discussions about what concept to converge on. Those discussions are taken into spring break when the team convenes at the BTH campus and visits the corporate for a presentation and conversation with an extended group of company staff. During this period, based on deeper discussions and from feedback from the partner, the team decides what concept to converge on. 
Moving into spring quarter, every focus is on the delivery, meaning bringing the solutions to a finished presentable prototype stage. For the final event, the EXPE (Stanford University Design EXPErience), they must consider how to present the solution and convince the audience about the value the solution offers. Not only does the EXPE prototype need to be real and realistic, it also needs to match well with the identified user needs, the selected problem space and the user desirability, business viability and technical feasibility. Telling the story, also considering business and systems factors, is almost as important as presenting a well-engineered product, so the team also needs to design and print posters and brochures, prepare, and rehearse a presentation, and create a demo booth for the design fair.

On the first Thursday of June, EXPE is held, with a broad array of onlookers, ranging from corporate liaisons, other academics and students, and Silicon Valley venture capitalists. The whole project is then wrapped up in the final documentation.

\subsection{Why ME310 matters to the corporate partner}

Every year the ME310 student teams are given corporate project prompts with broad challenges, relevant to the corporate's strategy and vision, and are guided through a design thinking-based work process, much different from the corporate's own stage-gate-based product development process (Cooper, 2009). This approach enables teams to see the complete, holistic user context, unbiased by existing offering limitations, a perspective not based on preconceived industry understanding or existing customer's feedback and therefore both the problem space and the solution space is larger than what it tends to be for the typical corporate employee. The corporate's prompts are designed to be complex and explorative, posing questions in areas where straightforward answers do not exist, albeit focusing on contexts (e.g., urban mining, autonomous machines, electrification, connectivity, waste and recycling industry, safety) that are of interest for future value propositions. These prompts are seen with some scepticism within the corporate, with a long history of thinking in terms of products rather than integrated product-service systems. By having the team of students, that are not at all biased by existing business, explore new possibilities of solutions, it is possible to learn many innovation opportunities beyond the initial expectations. By engaging and interacting with the students throughout the school year the company can learn about the context, the users, the problem space, different conceptual solutions, engineering tools and methods, communication platforms and collaboration styles. ME310 participation is for a corporate a learning experience, a networking experience, and new business opportunities.

\subsection{Observations from previous years}

The authors have interviewed the students during several years with the aim to understand distributed team dynamics versus performance, and individual expectations versus experiences. This material is organized throughout the school year timeline, forming a general "team journey map", which is part of future work. During previous "normal" years, the following general patterns are identified:

- Teams spending time with each other outside the schedule during the week when they are gathered at Stanford are better at staying in touch throughout the year and are therefore able to utilize the full team's insights and capabilities better. The years when team members only show up occasionally for the hang out time, and seemingly want to be elsewhere, reflected that lack of connectedness by more frustration and conflict, or disconnect later in the year.

- Teams that do not get the "one global team" feeling will not reach as far as the ones collaborating throughout the journey. Some teams ended up with one Stanford delivery and one BTH delivery and connected these through storytelling.

- $\quad$ Teams seem to reach further with their solution when the final convergence does not happen until the Stanford students visit in Sweden during spring break, therefore any attempt to converge prior to the spring break are challenged.

- Mutual interest for each other's work and respect for each other's competences within the local teams, and in the global team significantly increases the quality of the final EXPE delivery, why the supporting cohort made sure the teams set up lightweight knowledge sharing technologies (Bertoni \& Larsson, 2011) and conduct joint meetings from the get-go.

- The quality of the EXPE delivery is higher when the full team engages in intense, co-located collaboration to get the showcase prototype and the auditorium presentation ready for EXPE. This meant that the BTH students arrived at Stanford 3-4 weeks prior to the EXPE. An intense 
and memorable experience for the team, and a significant time and money investment for all involved.

- Teams with a few individuals being appointed, or self-appointed, as leaders tend to lose a few individuals in the teamwork, so the team breaks up in subgroups. Teams where all feel equally responsible tend to stay cohesive and involved throughout the project.

- Teams that take on an ownership role, and act as this is their project, their shared accomplishment and do not just accept what the teaching teams are telling them become more cohesive and end up prouder and more satisfied with their experience.

\section{RESEARCH APPROACH}

This paper reports on a qualitative single case study (Yin, 2009) into an ME310 global engineering design student project between Stanford and BTH. The aim was to investigate touchpoints and reasons for aspects that deviated from the normal course of events because of the restrictions placed upon the students following coronavirus lockdowns.

During the year, as in previous years, the researchers have, as part of being in the supportive cohort, followed the students' work, information creation and parts of their communication. This information, as well as the interactions with the students, were the foundation for reflection notes, covering this year as well as the previous seven years, which the authors wrote independently and shared. As this year was unique the authors decided to perform semi-structured interviews with 7 out of the 9 students. The interviews were conducted in retrospect shortly after the project was concluded. The indepth insights from the 2019/2020 year were compared with the identified general patterns from previous years, and this paper is presenting an initial Covid-19-year specific result, with more to uncover.

\section{OBSERVATIONS DURING THE COVID-19 YEAR}

ME310 in 2019/2020, started as any other year, with four Stanford students and five BTH students. The global gathering at Stanford's campus took place late in the fall semester, with lectures, team collaboration and presentations. The winter semester begun the same way as previously, with a global team showing promising team dynamics and performance, like the highest performing teams before. In February the coronavirus pandemic caused all Stanford students' trips to their global partners to be cancelled. This eliminated the usual visit to the corporate's headquarter, a previously identified important instance leading to the final convergence. Next pandemic effect was that all Stanford students were sent away from campus and continued their education remotely, in lockdown, geographically dispersed across the United States, and with limited resources for prototyping. The BTH students were also moved to distance learning, but with Sweden's less restrictive corona strategy they could do some prototyping in their kitchens until the campus lab facilities were opened, shortly before EXPE. This situation was devastating for the team that already felt they were behind schedule. They had not converged and were prepared for intense, focused work during the time together in Sweden - and now, in their homes they all expressed disappointment and hopelessness.

\subsection{The Beginning phase}

The prompt, focusing on "the future of waste industry", with the addendum of the Volvo "triple zero" vision (zero accidents, zero emissions, zero unplanned stops), was presented to the global team in October and was considered very wide, which the students retrospectively understood was intentional. As they found it difficult to make sense of, they simply got started riding along with garbage trucks and looked for different user pain points and needs. In their search for the "golden nugget", they explored numerous areas and the challenge was to decide when they had done enough research and should move on. They demonstrated good connectedness and worked diligently with the problem space exploration, and shared insights openly and frequently. The team was deep into the need-finding at the time for the global summit and presented a first functional prototype, targeting a user persona far outside intended industry segment. Nobody in the team were committed to that solution, and expressed stress over not yet being close to finding their "it" (Savoia, 2019). This did not worry the surrounding cohort, as early convergence has shown to be more limiting than late convergence when the team has found their "it". The team was despite their worries acting as one cohesive global team, loyal to each 
other and highly motivated. Below quotes from the team members during the beginning phase provides a good illustration of the team dynamics at that stage:

"The Swedes came over in late November and we already felt like one team because of all the needfinding and benchmarking we had done and shared."

"Without that kick-off week, we wouldn't have any collaboration at all. Just a few meetings here and there."

"And when we are one global team, then you cannot compete with each other."

\subsection{The Middle}

During the beginning of the winter semester, the students at the two schools usually struggle to collaborate effectively. While the BTH students are challenged to have solid reasoning behind every concept they explore, and consider integrated product-service-systems, and circularity, the Stanford teaching team is pushing for rapid physical product prototyping with quick iterations. The differences are required as the academic education in the countries is different and causes confusion between the student teams, which the students describe like this:

"The Stanford teaching team was constantly pushing for deliverables and convergence while the BTH teaching team pushed for critical thinking and further exploration, more divergence. For us, as one team this was stressful and confusing."

"During the winter semester we didn't collaborate, because of the differences in courses, but we kept informing each other, and encouraged each other, for us at Stanford it felt like we were only satisfying the Stanford teaching team's requests."

The team had several concepts going on in parallel, and these were generating further questions regarding desirability, feasibility, viability, scalability - and sustainability. They were late with convergence compared to other teams, and worried about a time-pressured spring quarter. Then the coronavirus hit, and with an already challenging situation regarding convergence and now not getting together in Sweden as they had planned for and looked forward to, they felt despair. At first, the Stanford students planned to rent a place to stay at to get focused collaboration time, but when they were sent away from campus, they ended up far apart. The BTH students also had limited access to campus, with online education, but stayed in the same city.

All this could have been detrimental for the team's progress but turned out to work well for them. Thanks to the struggle with convergence, they were all focused and continued to work intensely around the clock to get to the decision. Already oriented towards the waste industry and with one concept being water-soluble packaging, the situation with the coronavirus causing shortage of personal protection equipment provided a new both clear and urgent direction for them. All students described afterwards a strong feeling of epiphany, finally they had found their "it". The team reached out to connections within the waste industry to learn if the solution had potential and were encouraged to continue with this solution. Waste management workers use 3-5 pairs of gloves per 8-hour shift and by using water-soluble polyvinyl alcohol (PVA) gloves, facilities could reproduce fresh new gloves after contamination, locally in their own circular mini factory. Unlike single-use gloves, the PVA based ones will be non-toxic and biodegradable. A circular system reduces the amount of landfill caused by PPE, in-house glove manufacturing decreases dependence on external supply chains, and a mobile production system could allow gloves to be made anywhere.

Below are a few quotes from interviews with the students, regarding the convergence.

"We postponed convergence because we didn't LOVE any of our concepts."

"We spent 5 hours a day for 2-3 weeks just trying to push concepts further, and none of them felt right, then covid hit, gave us the PPE crisis and that was exactly what we needed, suddenly we found our "IT", we all felt it, and knowing that we were late with our convergence we were so relieved and also knew that we needed to move quickly, we all had a strong sense of urgency."

"We made many pivots during the journey. When Covid-19 appeared with all the media reports about PPE shortages we already had an idea about a circular system, but for packaging material. We struggled a lot with this and wanted to keep working on it, and when the pandemic came about, we thought - why isn't there a circular system for health care PPE?" 
"Selecting this concept, which was directed towards a major problem in the wake of Covid-19 we also felt an urgency not just for our studies, but also to deliver a solution that provides something that the world needs."

"We were already mobilized, worked closely together and had connectedness like no other team, covid couldn't stop us."

"We felt this is our IT and the deeper we went into that problem space with both hospitals and the waste industry it was so clear it made sense."

\subsection{Delivery phase}

Once the decision was made the team got busy designing, building, and testing prototypes and preparing for the first ever online EXPE. Previous years the teams that get together on Stanford campus and collaborate intensely to prepare for the EXPE day are the ones that reach the farthest. This year there was no on-campus time to hope for, and for this team, there was no need. This team showed no tendency of using the pandemic as an excuse.

Thanks to their late convergence they had a strong sense of urgency, were mobilized and shared tasks even utilized the time differences to their advantage. It was also observed that in this team nobody was in charge, at any point. Instead, the team members were dynamically taking turns and if someone needed to take a break, another team member stepped in and if someone seemed disengaged the team naturally reengaged that individual. Another observation throughout the year was that there were no critical comments about the other school or the other students. Maybe the pandemic came in and played the role of an evil enemy, galvanising them? Of course, without the usual social life on their respective campuses, the students had more time for the project and more time to connect with teammates in different time zones. The students' experience of the delivery phase is reflected in the following quotes:

"Thanks to the lockdown we broke up the Stanford team, and became one global team, and then we worked around the clock."

"We worked task-oriented so when somebody went passive, he or she would get tasks and that brought them right back into action."

"You need a bit of information to be able to discard, in the same way as when you select to keep something. A lot of work is down to doing research."

"The situation forced us to collaborate in other ways. Otherwise, we would have the Swedes meeting every day and then we would have discussed it once a week with the Americans. Now we had meetings every other or even every day to bounce ideas with each other."

"We were the ones that could build stuff since we had access to facilities and tools. But that didn't mean that the Americans were disconnected from that part of the project. They were drawing the cad models, and then we built what they had been drawing. We were always working on the same project, even though everyone didn't have the same opportunities to realize the machine. Some people found joy in doing material testing and investigating material properties, then they did that. The ones who liked CAD could do that. So, we utilized what people enjoyed doing."

"Keep everyone emotionally connected to the prototypes that are built in Sweden - even when you are sitting in Hawaii and have been doing some CAD models, you are still involved."

This team demonstrated strong connectedness, and a positive attitude towards each other, even during stressful, challenging times (Jung \& Leifer, 2011). The authors were able to observe the mix of formal task-oriented interaction together with informal communication (Törlind \& Larsson, 2002) during the most intense preparation work before EXPE. They managed to deliver a near-perfect EXPE experience, in terms of presentation, in terms of online marketing material and in terms of a fully functioning prototype, and they did it online, during a pandemic.

The students themselves said:

"I was so proud of us, we had a needed and sustainable solution, and we had tested all aspects of it."

"It was a rough year, we had moments when we thought we were failing when we felt that we weren't meeting the expectations from the teaching teams and the corporate, but we kept working and, in the end, we felt proud and accomplished." 
"During the EXPE presentation people thought this was a prototype and solution that was timely, given Covid-19, but also for the future where these materials are problematic since it represents an old way of thinking where you produce, use, discard and never see it again."

\subsection{Concluding the year}

At the end of the school year, the students looked back at a very rewarding experience and the work with their solution continues. During the retrospective interviews with the students, they all expressed pride and gratitude, and they all mentioned that post Covid-19, they will get together and celebrate an outstanding accomplishment during an outlandish year. A few reflections by the students below:

"We spent two-thirds of the year just dismantling the problem space and that was something I really appreciated."

"Such a great learning experience, both the design thinking modes and the team dynamics, especially since we had such a good team."

The Covid-19-year ME310 experience provided perspectives and insights that are partly captured in this paper. This global team of ambitious students started off the year in an expected promising way, got their expected course journey dramatically disrupted by the global pandemic and were after that surprisingly successful. They did not use the pandemic situation as an excuse, they pushed themselves and took care of the team spirit, and their full-year result was what we call a triple wow. Previous year's observations showed that this team was likely to fail, but they didn't.

\section{CONCLUSIONS}

Guiding a geographically dispersed student design team working at the forefront of innovation with wicked problems in capstone courses is anything but piecemeal. Many actions that orchestrate the project and team are based predominantly on reflections on the actions undertaken with experience, as an expansion on design thinking theory, which is accumulated for several years. Every year more lessons are learned, some of them challenging previous truths, and the authors' ambition is to address and analyse those deeper to develop recommendations for other engineering capstone courses. The year affected by the coronavirus gave new surprising and unexpected insights that overthrew some previous "truths" and assumptions about what ought to be achievable under those circumstances. Sending students into lockdown and taking away their prototyping realisation resources ought to be detrimental to the performance and morale in the team. But, as this team demonstrated, the global crisis provided purpose, momentum, and a sense of urgency, and the team was able to reap the benefits of being dispersed across even more time zones to coordinate efforts according to who could best address each issue. This was enabled by a solid build-up of the global team, bonding to build trust already before the situation changed, and therefore not directly comparable with previous or any following year. This team demonstrated the following, throughout the year, before and after the coronavirus hit:

- $\quad$ They liked each other, all of them enjoyed spending time together outside the schedule. The early together-time built trust and respect, which is easy to do when meeting in person. The core function is that they need to hang out in a way that it is not forced upon them so they just gladly will leave at the first opportunity, which will be a challenge to facilitate when restrictions are at the outset.

- They felt equally responsible, nobody was appointed or self-proclaimed as leader. The nature of the restrictions and their late mutual convergence fuelled momentum throughout the team, utilizing the strengths of what everyone could offer. Everyone leaned in and when someone ran the risk of falling out, their friends helped. This sense of urgency and respectful division of tasks should also be sought from the cohort in normal years when the external factors may be more beneficial.

- They spoke highly of each other, even during challenging times, and jointly utilized the entire team's different skills and energy levels to get every task done. It was clear that they "suffered for" each other and while finding a common goal in the PPE shortage, they also found common ground in having a "common enemy" in their perceived scepticism from the teaching staff. When reflecting on actions to take, the cohort can play the devil's advocate on the process. 
- They utilized time zone differences and the extraordinary geographical distribution as opportunities. By working around the clock, relaying ongoing work to each other until the task was completed, they were possibly even more productive than a co-located team would be.

In the spirit of Professor Bernie Roth, cofounder of Stanford d.school, the following poem, written by ME310 Professor of Mechanical Engineering Mark Cutkosky, provides comforting words for students in despair (Sheppard, u.d.):

"The days are growing short and grey. The project isn't what you'd thought. The teaching team wants C.F.P.s, but your sponsor has his own ideas (some are reasonable, some are not). Too little time, too many questions, too many constraints. You're at a loss... But HEY, it's O.K. because... you're the BOSS!"

\section{FUTURE WORK}

With merely one year and one team experience of a pandemic affected ME310 project, it is not possible to conclude that these learnings are repeatable. They challenge previous year's hypotheses and future work will include an exploration on whether a more structured and real-time sharing of observations among the cohort would benefit the cohort calibration, to tailor coaching and facilitation, each year.

In the future work the authors also aim to revisit all previous year's documentation throughout the three- semester course "journey" and map out student experience and team performance data to further develop understanding of what makes teams achieve triple wows and what causes glitches in the teams. The team journey map, connected to the previously defined triple loop learning concept (Leifer \& Steinert, 2011), and the importance of T-shaped individuals, will be part of a research framework for the authors to explore how to develop engineering education further.

It would also be of value to explore the evolution of the definition of deep competence, and potentially provide insights into how globally distributed teams can tackle today's and future generations most critical systemic wicked problems, related to climate change, social justice, and sustainability.

\section{ACKNOWLEDGMENTS}

We would like to thank the ME310 students for their time, commitment and honesty in dialogues, semi-structured interviews, and surveys. A special note to the 2019/2020 team - we owe you that dinner, don't forget! We would also like to thank Volvo Group for sponsoring this unique learning experience over the years. Without the financial contribution nothing of this would have been possible.

\section{REFERENCES}

Bushnell, T., Steber, S., Matta, A., Cutkosky, M., Leifer, L. (2013), "Using a "dark horse" prototype to manage innovative teams", 3rd International Conference on Integration of Design, Engineering \& Management for Innovation, Porto, Portugal, 4-6th September 2013. http://doi.org/10.13140/2.1.2361.7602

Bertoni, M., Larsson A. (2011), " Engineering 2.0: an approach to support cross-functional teams in overcoming knowledge-sharing barriers in PSS design", International Journal of Product Development, Vol. 15, pp 115134. https://doi.org/10.1504/ijpd.2011.043664

Carleton, T. (2019), ME310 at Stanford University: 50 Years of REDESIGN (1967-2017), Innovation Leadership Publishing, San Carlos.

Carleton, T. and Leifer, L. (2014), "Stanford's ME310 Course as an Evolution of Engineering Design.", Competitive Design, Proceedings of the 19th CIRP Design Conference, Cranfield University, 30-31 March. http://doi.org/10.21278/idc.2018.0503

Cooper, R. (2009). How Companies are Reinventing Their Idea-to-Launch Methodologies. ResearchTechnology Management., 52, 47-57. http://https://dx.doi.org/10.1080/08956308.

Dym, C. (2005). "Engineering Design Thinking, Teaching, and Learning", Journal of Engineering Education, Vol. 94, pp. 103-120. http://doi.org/10.1002/j.2168-9830.2005.tb00832.x

Eris, O. (2003). "Asking generative design questions: a fundamental cognitive mechanism in design thinking", Proceedings of the international conference on engineering design, Stockholm, August 19-21. http://doi.org/10.1007/978-1-4419-8943-7_2

Jackson, N. J. and Buining, F. (2010). "Enriching Problem-based Learning through Design Thinking”, New approaches to problem-based learning: revitalizing your practice in higher education. London: Rutledge, pp. 269-293. http://doi.org/10.7771/1541-5015.1519 
Jung, M. F. and Leifer, L. J. (2011). ”A method to study affective dynamics and performance in engineering design teams", 18th International Conference on Engineering Design - Impacting Society Through Engineering Design, Copenhagen, 15-18 August. pp. 244-253. http://doi.org/10.1145/1015530.1015551

Lande, M. and Leifer, L. (2009). "Student representations and conceptions of design and engineering", Frontiers in Educations Conference, 39th IEEE, pp. 1-2. http://doi.org/10.1109/FIE.2009.5350576

Lande, M. and Leifer, L. (2010). "Incubating engineers, hatching design thinkers: Mechanical engineering students learning design through Ambidextrous Ways of Thinking”, ASEE Annual Conference and Exposition, Conference Proceedings, Louisville, June 20-23. http://doi.org/10.18260/1-2--16990

Larsson, A., Törlind, P., Karlsson, L., Mabogunje, A., Leifer, L., Larsson, T., Elfström, B-O. (2003). "Distributed team innovation - a framework for distributed product development", 14th international Conference on Engineering Design, ICED'03, pp. 321-322., Stockholm, August 19-21. http://doi.org/10.1007/978-3-540-69820-3_33

Leifer, L. and Steinert, M. (2011). "Dancing with Ambiguity: Causality Behavior, Design Thinking, and TripleLoop-Learning”. Information-Knowledge-Systems Management, pp. 151-173. http://doi.org/10.3233/IKS2012-0191

Savioa, A. (2019). “The Right It: Why So Many Ideas Fail and How to Make Sure Yours Succeed”, HarperOne, New York.

Schar, M., (2012). ME310 Corporate Brochure 2012. Available at: https://web.stanford.edu/group/me310/me310_2018/ME310CorporateBrochure2012-13.pdf (accessed December 4, 2020)

Sheppard, Sheri., (u.d). Available at: https://labs.ece.uw.edu/seal/internal/files/BERNIE.pdf (accessed March 2021)

Steinert, M. and Leifer, L. (2012). 'Finding One's Way': Re-Discovering a Hunter-Gatherer Model based on Wayfaring”, International Journal of Engineering Education, 28(1), pp. 251-252.

Törlind, P. and Larsson, A. (2002). "Support for Informal Communication in Distributed Engineering Design Teams". Proceedings of the 2002 International CIRP Design Seminar, May 16-18, Hong Kong. doi.org/10.5585/iji.v6i2.245

Ulwick, T., 2017. What Is Jobs-to-be-Done? Available at: https://jobs-to-be-done.com/what-is-jobs-to-be-donefea59c8e39eb (accessed December 4, 2020)

Yin, R. K. (2009). "Case study research: Design and methods”. 4th revision. Sage Publications 